\title{
DEVELOPMENT OF SPECTROPHOTOMETRIC METHOD FOR DETERMINATION OF GERMANIUM
}

\author{
Li Zaijun ${ }^{1 . *}$, Zhou Xia', Liu Huizhen' and Pan Jiaomai ${ }^{2}$ \\ 'College of Chemical and Materials Engineering, Southern Yangtze \\ University, 170 Hui He Road, Wuxi 214036, The People's Republic of \\ China \\ 'Department of Chemistry, East China Normal University, 3663 Zhong \\ Shan Road (N), Shanghai 200062, The People's Republic of China
}

\begin{abstract}
Germanium is a nutritional element for humans and animals; it has very important biological functions, so plants containing a high level of germanium and many synthesized organic germanium compounds have been widely applied in the food and medicine industries recently to improve our health. Germanium was also used as an alloying element in the semiconductor industry and as a catalyst in the plastics industry. The determination of trace germanium has received increasing attention. Analytical methods used for the determination of germanium have mainly been molecular spectrophotometry $/ 1,2 /$ and atomic absorption spectrometry 13-5/. Among these, molecular spectrophotometry was always employed in routine germanium analysis owing to its simplicity and economy of use. In the last ten years, many new color reaction systems and technologies have been developed for spectrophotometric determination of germanium. As compared to the old color system using phenylfluorone as the color reagent, the analytical characteristics of the new color system are remarkably improved in sensitivity, selectivity and rapidity; some reagents are sensitive and selective enough to directly determine trace amounts of germanium in complex samples such as foods, soil and coal. In this paper, the literature has been surveyed for the methods of spectrophotometric determination of germanium reported from 1996 to 2005 and presented here in the form of a
\end{abstract}

\footnotetext{
"Corresponding author, e-mail address: Zaijunli(u26.3.net .
} 
review concerning color reaction system, separation and pre-concentration and new spectrophotometric analysis technologies.

\section{COLOR REACTION SYSTEM}

In the last ten years, many new color reaction systems have been developed for spectrophotometric determination of germanium; these are listed in Table 1. Although each system has its advantages and disadvantages with respect to sensitivity, selectivity and rapidity due to using different analytical reagents, in general, the new color systems have very high sensitivity, the apparent molar absorption coefficient of the complex was more than $10^{5} 1 . \mathrm{mol}^{-1}$. $\mathrm{cm}^{-1}$ for most color systems. For common metal ions, color reaction systems show excellent selectivity; their tolerated limit usually exceed $\mathrm{mg}$ level. The main interference comes from the molybdenum, tungsten, titanium, tin, antimony, gallium, indium, zirconium, niobium and tantalum et al. metal ions because they can react with the reagent sensitively in very similar conditions, in which the absorption spectra of the complexes overlap seriously (see Table 2). Therefore, when the above metal ions coexist in the samples, a prior separation procedure was required strongly in order to obtain a reliable result; almost all color systems were difficult to be applied to directly spectrophotometric determination of trace germanium in complex samples such as soil, blood and alloy. In order to overcome the above problem, continuous research is going on to find more sensitive and selective reagents for determination of germanium and to study the effect of substituent groups on the analytical characteristics of the reagent. In the last five years, a number of new chromogenic reagents were designed and synthesized in the laboratory, and the reaction of each reagent with germanium(IV) was investigated in detail, respectively $12,20 \%$. Experiments indicated that new reagents were obviously more sensitive and selective than other reagents in the literature. Among these, 9-(2-hydroxy -5-pmethylphenylazo)phenylfluorone (HMPAPF) is best; its molecular structure is shown in Fig. 1. The color system has excellent analytical characteristics in sensitivity, selectivity and rapidity. In 6.omol..$^{-1} \mathrm{H}_{3} \mathrm{PO}_{4}$ medium, HMPAPF reacts with germanium(IV) to form a red complex in the presence of TritonX100( see Fig. 2); all ions studied can be tolerated in considerable amounts, its sensitivity and selectivity are markedly superior to the other derivatives of 
phenylfluorone. The proposed method has been successfully applied to determine trace germanium in foods, plants and soils without using separation and preconcentration process and organic solvent as masking agents; it is one of the most sensitive and specific reagents for spectrophotometric determination of germanium found to date (see Table 2).<smiles>Cc1ccc(/N=N/c2ccc(O)c(-c3c4cc(O)c(=O)cc-4oc4cc(O)c(O)cc34)c2)cc1</smiles>

Fig.1: The molecular structure of 9-(2-hydroxy -5-pmethylphenylazo)phenylfluorone

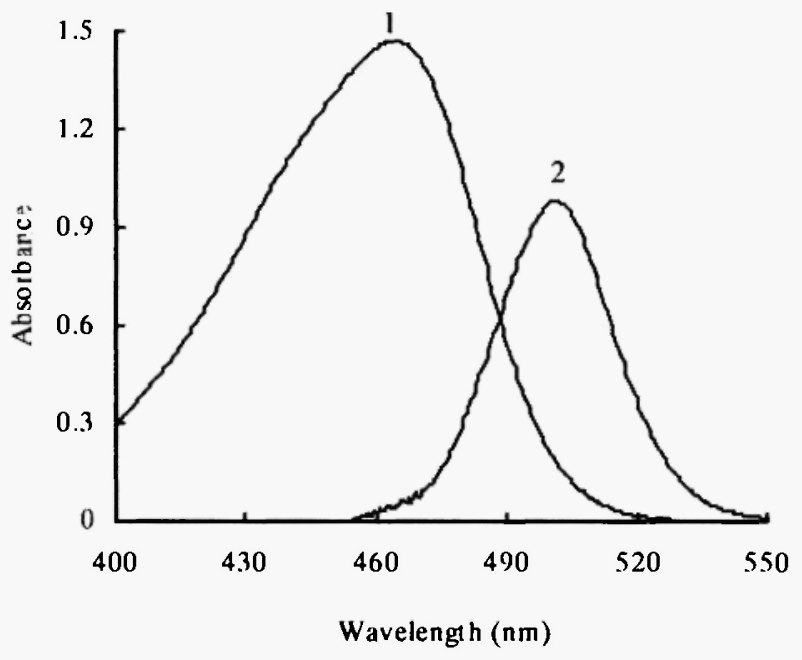

Fig. 2: Absorption spectrum

1. The reagent against water, 2 . The complex against corresponding reagent blank solution 


\section{Table 1}

Review of new color reaction system for spectrophotometric determination of germanium in the past ten years

\begin{tabular}{|c|c|c|}
\hline Reagent & Remarks & Ref. \\
\hline $\begin{array}{l}\text { 2-Hydroxy-3-methoxy- } \\
\text { phenylfluorone (HMPF) }\end{array}$ & $\begin{array}{l}\text { (1) In } \mathrm{H}_{2} \mathrm{SO}_{4} \text { medium, germanium(IV) reacts } \\
\text { with } \mathrm{HMPF} \text { to form red complex with a } \\
\text { maximum absorption peak at } 505.5 \mathrm{~nm} \text { in the } \\
\text { presence of CTMAB. } \\
\text { (2) The apparent molar absorption coefficient } \\
\text { of the complex is } 1.0 \times 10^{5} 1 \mathrm{~mol}^{-1} \mathrm{~cm}^{-1} \text {, Beer's } \\
\text { law is obeyed in the range of } 0-13 \mu \mathrm{g} \text { of } \\
\text { germanium in } 25 \mathrm{ml} \text { of solution. } \\
\text { (3) The method was applied to determination } \\
\text { of germanium in boiler smoke dusts. } \\
\text { (4) Molybdenum, tungsten, titanium, tin, } \\
\text { antimony, gallium, indium, zirconium, } \\
\text { niobium and tantalum interfere with the } \\
\text { determination of germanium seriously. }\end{array}$ & 6 \\
\hline Phenylfluorone (PF) & $\begin{array}{l}\text { (1) In presence of ascorbic acid, } \\
\text { hydroxylamine and CTMAB, PF reacts with } \\
\text { germanium(IV) to form a orange complex } \\
\text { with a maximum absorption at } 505 \mathrm{~nm} \text {. } \\
\text { (2) Beer's law is obeyed in the range of 1.0- } \\
5 \mu \mathrm{g} \text { of germanium in } 25 \mathrm{ml} \text { solution } \\
\text { (3) The method has been applied to determine } \\
\text { the trace germanium in arborescens with } \\
\text { satisfactory results } \\
\text { (4) Molybdenum(VI)(0.05mg), vanadium(III) } \\
\text { (0.1mg), of antimony (III) (0.01mg), } \\
\text { chromium(III)( } 0.1 \mathrm{mg}) \text { and } \\
\text { tungsten(VI)( } 0.02 \mathrm{mg}) \text { have very low } \\
\text { tolerated limit. }\end{array}$ & 7 \\
\hline $\begin{array}{l}\text { 2,4-Dichlorophenyl- } \\
\text { fluorone (DCPF) }\end{array}$ & 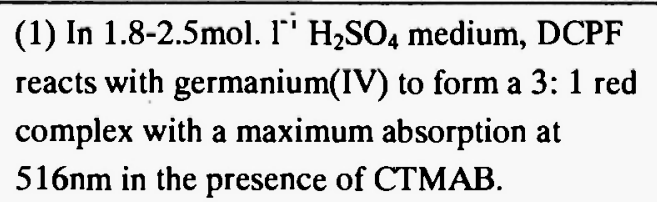 & 8 \\
\hline
\end{tabular}


(2) The apparent molar absorption coefficient of the complex is $1.38 \times 10^{5} 1 . \mathrm{mol}^{1} . \mathrm{cm}^{-1}$, Beer's law is obeyed in the range of $0-12.5 \mu \mathrm{g}$ of germanium in $25 \mathrm{ml}$ solution.

(3) Proposed method has been applied to determine germanium in coal.

(4) Iron(III)(0.5mg), copper(II)(0.05mg), aluminium(III)(0.05mg), vanadium(IV)(0.05mg), thorium(VI)(0.05mg), chromium(III) $(0.01 \mathrm{mg}$ ), titanium(IV)(0.01 mg), zirconium(IV)(0.01 mg), lanthanum(III)(0.02mg), yttrium(III)(0.02), niobium(IV)(0.005mg), molybdenum(VI)(0.05mg) and gold(III) $(0.05 \mathrm{mg})$ have a very low tolerated limits, $\mathrm{H}_{2} \mathrm{O}_{2}$ interfere with determination of germanium.

3,5-Dimethoxy-4hydroxyphenylfluorone (DMOHPF)
(1)In 1.8-4.2mol. ${ }^{-i} \mathrm{H}_{3} \mathrm{PO}_{4}$, DMOHPF reacts $\quad 9,10$ with germanium(IV) in the presence of TritonX-100 to form a 2:1 red complex with a maximum absorption at $505 \mathrm{~nm}$.

(2) The apparent molar absorption coefficient of the complex is $1.8 \times 10^{5} 1 . \mathrm{mol}^{-1} . \mathrm{cm}^{-1}$, Beer's law was obeyed in the range of $0-7 \mu \mathrm{g}$ of germanium in $25 \mathrm{ml}$ of solution.

(3) The method has been used satisfactorily to determination of trace germanium in tea and some medicines.

(4) Color reaction system has very good selectivity, some metal ion such as titanium(IV)(0.8mg), zirconium(IV)(1.0mg) and molybdenum(VI)( $0.3 \mathrm{mg})$ can be tolerated

p-Chlorophenylfluorone (1) In the presence of mixed surfactants of 11 Tween 80 and CTMAB, $p$-CPF reacts with germanium(IV) to form a red complex with a 


\begin{tabular}{|c|c|c|}
\hline & $\begin{array}{l}\text { maximum absorption at } 510 \mathrm{~nm} \text { in a } 0.36- \\
1.0 \text { mol. } .^{-1} \mathrm{H}_{2} \mathrm{SO}_{4} \text { solution. } \\
\text { (2) The apparent molar absorption coefficient } \\
\text { of the complex is } 1.48 \times 10^{5} 1 . \mathrm{mol}^{-1} . \mathrm{cm}^{-1} \text {, } \\
\text { Beer's law was obeyed in the range of } 0 \text { - } \\
10 \mu \mathrm{g} \text { of germanium in } 25 \mathrm{ml} \text { of solution. } \\
\text { (3) The method was applied to determine } \\
\text { germanium in ore residues. } \\
\text { (4) Titanium(IV)(0.1 mg), } \\
\text { tungsten(VI)(0.005 } \mathrm{mg}), \text { tin(II)( } 0.01 \mathrm{mg}) \text { and } \\
\text { molybdenum(VI)(0.002 } \mathrm{mg}) \text { have low } \\
\text { tolerated limits. }\end{array}$ & \\
\hline $\begin{array}{l}\text { 4,5-Dibromo-2-nitro- } \\
\text { phenylfluorone (DB-o- } \\
\text { NPF) }\end{array}$ & $\begin{array}{l}\text { (1) In } \mathrm{H}_{3} \mathrm{PO}_{4} \text { and Tween } 20 \text { medium, } \\
\text { Germanium(IV) reacts with DB- } o-\mathrm{NPF} \text { to a } \\
\text { 1:2 red complex with a maximum absorption } \\
\text { at } 540 \mathrm{~nm} \text {. } \\
\text { (2) The apparent molar absorption coefficient } \\
\text { of the complex is } 1.02 \times 10^{5} 1 . \mathrm{mol}^{-1} . \mathrm{cm}^{-1} \text {, } \\
\text { Beer's law was obeyed in the range of } 0-6 \mu \mathrm{g} \\
\text { of germanium in } 25 \mathrm{ml} \text { of solution. } \\
\text { (3) The method was applied to determine } \\
\text { germanium in coal stones } \\
\text { (4) A } 20 \text { min for color developing time was } \\
\text { required. } \\
\text { (5) Vanadium, gallium, uranium, cadmium, } \\
\text { chromium, niobium, tin, antimony and } \\
\text { molybdenum interfere with the determination } \\
\text { of germanium. }\end{array}$ & 12,13 \\
\hline $\begin{array}{l}\text { 2-Hydroxyphenylfluorone } \\
\text { (HPF) }\end{array}$ & $\begin{array}{l}\text { (1) In a micro emulsion medium containing } \\
\text { CTMAB, n- } \mathrm{C}_{4} \mathrm{H}_{9} \mathrm{OH}, \mathrm{C}_{5} \mathrm{H}_{12} \text { and water, } \\
\text { germanium(IV) reacts with HPF to form a red } \\
\text { complex, its maximum absorption lie at } \\
505 \mathrm{~nm} \text {. } \\
\text { (2) The apparent molar absorption coefficient } \\
\text { of the complex is increased from } 1.8 \times 10^{5} \text { to } \\
2.1 \times 10^{5} 1 . \mathrm{mol}^{-1} \cdot \mathrm{cm}^{-1} \text {, Beer's law is obeyed in } \\
\text { the concentration range of } 0-3.0 \mu \mathrm{g} \text { of }\end{array}$ & 14 \\
\hline
\end{tabular}


germanium in $25 \mathrm{ml}$ of solution.

(3) The method has been successfully applied to determine germanium in geological samples.

Trimethoxyphenylfluorone (TMPF)
(1) The method is based on the reaction of 2 germanium with a new reagent TMPF in the presence of Triton X-100. The absorbency of the complex at $505 \mathrm{~nm}$ increases linearly with concentration up to $0.24 \mu \mathrm{g} \mathrm{ml}^{-1}$ germanium in aqueous solution with a relative standard deviation (R.S.D.) of $1.02 \%$.

(2) The apparent molar absorption coefficient of the complex, the limit of quantification and limit of detection were found to be $1.7 \times 10^{5} 1$ $\mathrm{mol}^{-1} \mathrm{~cm}^{-1}, 0.70$ and $0.21 \mathrm{ng} \mathrm{ml}^{-1}$, respectively.

(3) The influences of metal ions on the determination of germanium were investigated; all foreign ions studied, could be tolerated in considerable amounts, $50 \mathrm{mg}$ of calcium and magnesium, $100 \mathrm{mg}$ of iron and aluminium, $60 \mathrm{mg}$ of nickel, $8 \mathrm{mg}$ of magnesium and $1.0 \mathrm{mg}$ of lead do not interfere with the determination of $1.0 \mathrm{ug}$ of germanium, so the selectivity is superior to published methods, especially, with regards to titanium, zirconium, tin, molybdenum and tungsten, which always interfere with the determination of germanium in other methods.

(4) The color reaction system is simple and stable. The reaction of germanium with TMPF is complete within $\mathbf{3 0} \mathrm{min}$ and the absorbency of the complex remains almost constant for at least $24 \mathrm{~h}$ in a phosphoric acid medium.

(5) The synthesis of TMPF and the pre- 


\begin{tabular}{|c|c|c|}
\hline & $\begin{array}{l}\text { concentration of low germanium } \\
\text { concentrations were also investigated in } \\
\text { detail. The proposed method has been applied } \\
\text { to determine traces of germanium in foods } \\
\text { with satisfactory results. }\end{array}$ & \\
\hline $\begin{array}{l}\text { 3,5-Dibromo-4-hydroxy- } \\
\text { phenylfluorone (DBHPF) }\end{array}$ & $\begin{array}{l}\text { (1) In } \mathrm{HCl} \text { medium, DBHPF reacts with } \\
\text { germanium(IV) to form a red complex with a } \\
\text { maximum absorption at } 518 \mathrm{~nm} \text { in the } \\
\text { presence of CTMAB. } \\
\text { (2) The apparent molar absorption coefficient } \\
\text { of the complex is } 1.75 \times 10^{5} 1 \mathrm{~mol}^{-1} \mathrm{~cm}^{-1} \text {, } \\
\text { Beer's law is obeyed in the concentration } \\
\text { range of } 0-10 \mu g \text { of germanium in } 25 \mathrm{ml} \text { of } \\
\text { solution. } \\
\text { (3) The proposed method has been applied to } \\
\text { determine germanium in herbs. } \\
\text { (4) Molybdenum, tungsten, titanium, tin, } \\
\text { antimony, gallium, indium, zirconium, } \\
\text { niobium and tantalum interfere with the } \\
\text { determination of germanium seriously. }\end{array}$ & 15 \\
\hline $\begin{array}{l}\text { 9-(3,5-dibromo-4-(1,8- } \\
\text { dihydroxy-3,6- } \\
\text { disulfonicacid)- } \\
\text { naphthaaleneazo)phenyl- } \\
\text { fluorone (DBACPF) }\end{array}$ & $\begin{array}{l}\text { (1) In the presence of Tween } 60 \text {, the color } \\
\text { reaction of DBACPF with germanium, } \\
\text { DBACPF reacts with germanium to form a } \\
\text { red } 1: 2 \text { ternary complex in the medium of } \\
0.8 \mathrm{~mol}^{-1} \mathrm{H}_{2} \mathrm{SO}_{4} \text {. } \\
\text { (2) Its } \lambda_{\max } \text { is } 534 \mathrm{~nm} \text { and its apparent molar } \\
\text { absorption coefficient of the complex is } \\
1.76 \times 10^{5} 1 \mathrm{~mol}^{-1} \mathrm{~cm}^{-1} \text {, Beer s law is obeyed in } \\
\text { the range of } 0 \text { to } 6 \mu \mathrm{g} \text { of germanium in } 25 \mathrm{ml} \\
\text { of solution. } \\
\text { (3) The proposed method has been applied to } \\
\text { the spectrophotometric determination of } \\
\text { micro amount of germanium in coal with } \\
\text { satisfactory results. } \\
\text { (4) Molybdenum, tungsten, titanium, tin, } \\
\text { antimony, gallium, indium, zirconium, } \\
\text { niobium and tantalum interfere with the }\end{array}$ & 16 \\
\hline
\end{tabular}




\begin{tabular}{|c|c|c|}
\hline & $\begin{array}{l}\text { determination of germanium seriously, a } \\
\text { chloroform extract process was used to } \\
\text { improve the selectivity. }\end{array}$ & \\
\hline Diperonylfluorone (DPF) & $\begin{array}{l}\text { (1) In } \mathrm{H}_{2} \mathrm{SO}_{4} \text { medium, DPF reacts with } \\
\text { germanium(IV) to form a red complex with a } \\
\text { maximum absorption at } 530 \mathrm{~nm} \text { in the } \\
\text { presence of CTMAB. } \\
\text { (2) The apparent molar absorption coefficient } \\
\text { of the complex is } 1.16 \times 10^{5} \mathrm{I} \mathrm{mol}^{-1} \mathrm{~cm}^{-1} \text {, Beer } \\
\text { s law is obeyed in the range of } 0 \text { to } 8 \mu \mathrm{g} \text { of } \\
\text { germanium in } 25 \mathrm{ml} \text { of solution. } \\
\text { (3) Proposed method has been used to } \\
\text { determine germanium in foods with } \\
\text { satisfactory result. } \\
\text { (4) Niobium, tantalum and molybenum } \\
\text { interfere with the determination of } \\
\text { germanium seriously. }\end{array}$ & 17 \\
\hline $\begin{array}{l}o \text {-Nitrophenylfluorone (o- } \\
\text { NPF) }\end{array}$ & $\begin{array}{l}\text { (1) After conversion to the ternary complex } \\
\text { with } o \text {-nitrophenylfiuorone and sodium } \\
\text { dodecyl sulfate SDS, germanium could be } \\
\text { collected selectively on a membrane. The } \\
\text { membrane was then dissolved in a small } \\
\text { volume of } 2 \text {-methoxyethanol for directly } \\
\text { measuring absorbance. } \\
\text { (2) By pre-concentration, the limit of } \\
\text { detection for germanium was found to be } \\
0.4 \mu g .1^{-1} \text { (0.4ppb). } \\
\text { (3) The method was successfully applied for } \\
\text { the analysis of Chinese herb, natural water, } \\
\text { drinking water as well as urine samples. } \\
\text { (4) Molybdenum and lead caused positive } \\
\text { errors, which could be eliminated by masking } \\
\text { with oxalic acid or citric acid. }\end{array}$ & 18 \\
\hline $\begin{array}{l}\text { 9-(3,5-Dibromo-4-(2,4- } \\
\text { dihydroxy)phenylazo)- } \\
\text { phenylfluorone } \\
\text { (DBARPF) }\end{array}$ & $\begin{array}{l}\text { (1) The conditions of colour reaction of } \\
\text { Germanium(IV) with a new organic reagent } \\
\text { DBARPF in the presence of Tween } 60 \text { were } \\
\text { studied. It was found that germanium(IV) }\end{array}$ & 19 \\
\hline
\end{tabular}


reacts with DBARPF and Tween60 in 0.5$1.5 \mathrm{~mol}^{-1} \mathrm{HCl}$ medium to form a 1:2 red ternary micelle complex with maximum absorption at 532nm.

(2) The apparent molar absorption coefficient of the complex is $1.68 \times 10^{5} 1 \mathrm{~mol}^{-1} \mathrm{~cm}^{-1}$, Beer's law being adhered with in the range of $0-5 \mu \mathrm{g}$ of germanium in $25 \mathrm{ml}$ solution.

(3) The method has been applied to determine of germanium with satisfactory results.

(4) Tin, arsenic, lanthanum, titanium, molybdenum and zirconium interfere with the determination of germanium seriously.

9-(2-hydroxy-5-p-methyl-

(1) In 6.0 mol..$^{-1} \mathrm{H}_{3} \mathrm{PO}_{4}$ medium, germanium(IV) reacts with the reagent to (HMPAPF) form red complex with a maximum absorption at $501 \mathrm{~nm}$.

(2) The apparent molar absorption coefficient of the complex was found to be $2.1 \times 10^{5} 1$ $\mathrm{mol}^{-1} \mathrm{~cm}^{-1}$, OD $18 \mu \mathrm{g}$ of germanium was obeyed for Beer's law in $25 \mathrm{ml}$ of solution.

(3) Color system has excellent selectivity and stability. Most of the metal ions can be tolerated in considerable amounts without any masking reagents, especially great amounts of molybdenum and tungsten do not interfere with determination of trace germanium, its selectivity was superior to other reagents in literatures

(4) Proposed method has been applied to determination of germanium in some herbs with satisfactory results.

Ethyl rhodamine B(1) According to investigation of a color molybdogermaric acidreaction system of ethyl rhodamine $B$ PVS (ERB) molybdogermanic acid-PVA system, a highly sensitive spectrophotometric method for determination of trace germanium is reported. 
The maximum absorption wavelength of the ion-isssociated compound is at $584 \mathrm{~nm}$.

(2) The apparent molar absorption coefficient of the complex is found to be $5.44 \times 10^{6} 1 . \mathrm{mol}^{-}$ '.cm ${ }^{-1}$. Beer's law is obeyed in the range of 0 $0.22 \mu \mathrm{g}$ of germanium per $25 \mathrm{ml}$.

(3) The color of the aqueous solution is stable for at least $\mathrm{lh}$. The molar ratio of germanium (IV) to ERB in ion-associate is established to be 1:11. Germanium in ginseng can be determined by the proposed method with satisfactory results.

Rhodamine B-Germanomolybdenum blue-PVA

(1) Germanium was extracted into $\mathrm{CCl}_{4}$ from food and traditional Chinese medicine in a medium of $9-10 \mathrm{~mol}^{-1} \mathrm{I}^{-1} \mathrm{HCl}$, then extracted back into water. The complex can be stabilized for $24 \mathrm{~h}$. The context of germanium was determined by spectrophotometry at $580 \mathrm{~nm}$.

(2) The apparent molar absorption coefficient of the complex is $1.02 \times 10^{5} \mathrm{I} \mathrm{mol}^{-1} \mathrm{~cm}^{-1}$. Beer's law is obeyed in the range of $0-10 \mu \mathrm{g}$ of germanium per $25 \mathrm{ml}$. Its relative standard deviation is $5.9 \%$, recovery is $95-105 \%$. (3) This method has been used to determine germanium in some kinds of food, traditional Chinese medicine and ores.

Germanium(IV)Tungstate-Rhodamine B
(1) A color reaction of ion-association complex of the germanium(IV)- TungstateRhodamine B has been studied in 0.76$0.96 \mathrm{~mol}^{-1} \mathrm{I}^{-1} \mathrm{H}_{2} \mathrm{SO}_{4}$ medium and $0.08 \%$ PVA solution. The maximum absorbance of the ion-associated complex is at $585 \mathrm{~nm}$.

(2) The apparent molar absorption coefficient of the complex is $2.417 \times 10^{6} 1 \mathrm{~mol}^{-1} \mathrm{~cm}^{-1}$. Beer's law is obeyed in the range of $0-0.5 \mu \mathrm{g}$ of germanium per $25 \mathrm{ml}$ solution. 


\begin{tabular}{|c|c|c|}
\hline & $\begin{array}{l}\text { (3) The ion-association complex was stable } \\
\text { for at least } 60 \mathrm{~h} \text {. The molar ratio of } \\
\text { germanium to tungstate to Rhodamine } B \text { in } \\
\text { ion-association complex was established to } \\
\text { be } 1: 12: 4 \text {. } \\
\text { (4) The influence of } 38 \text { diverse ions was } \\
\text { examined. Most common ions do not } \\
\text { interfere. } \\
\text { (5)vThe method can be applied to the } \\
\text { spectrophotometric determination of micro } \\
\text { germanium in some ginseng with satisfactory } \\
\text { results. }\end{array}$ & \\
\hline $\begin{array}{l}\text { Molybdenum(VI)- } \\
\text { Antimonicgermanium }\end{array}$ & $\begin{array}{l}\text { (1) A color reaction of ion-association } \\
\text { complex of the molybdenum(VI)- } \\
\text { Antimonicgermanium has been studied in } 1.0 \\
\text { mol. } I^{-1} \mathrm{H}_{2} \mathrm{SO}_{4} \text { medium. The maximum } \\
\text { absorbance of the ion-associated complex is } \\
\text { at } 810 \mathrm{~nm} \text {. } \\
\text { (2) The apparent molar absorptivity is } \\
2.07 \times 10^{5} 1 . \mathrm{mol}^{-1} . \mathrm{cm}^{-1} \text {. Beer's law is obeyed in } \\
\text { the range of } 0-20 \mu \mathrm{g} \text { of germanium per } 25 \mathrm{ml} \\
\text { solution. } \\
\text { (3) Iron, vanadium, tungsten, chroomium, } \\
\text { copper, zinc, lead and arsenic interfere with } \\
\text { the determination of germanium, thus, a } \mathrm{CCl}_{4} \\
\text { extraction step was required to obtain a } \\
\text { reliable results. } \\
\text { (4) The method can be applied to the } \\
\text { spectrophotometric determination of micro } \\
\text { germanium in some vegetables with } \\
\text { satisfactory results. }\end{array}$ & 24 \\
\hline $\begin{array}{l}\text { Germanium(IV)- } \\
\text { tungstate-butylthodamine } \\
\text { B }\end{array}$ & $\begin{array}{l}\text { (1) A color reaction of ion association } \\
\text { complex of the germanium(IV)- tungstate- } \\
\text { butylrhodamine B was studied in the presence } \\
\text { of } 0.08 \% \text { polyrinylalcohol in } 0.96-1.16 \text { mol.l' } \\
{ }^{1} \mathrm{H}_{2} \mathrm{SO}_{4} \text { medium. The maximum absorbance } \\
\text { of the ion association complex is at } 580 \mathrm{~nm} \text {. }\end{array}$ & 25 \\
\hline
\end{tabular}


(2) The apparent molar absorption coefficient of the complex is $2.16 \times 10^{6} 1 . \mathrm{mol}^{-1} \cdot \mathrm{cm}^{-1}$.

(3) The ion association complex was stable for at least $48 \mathrm{~h}$. The molar ratio of germanium to tungsten to butylrhodamine B was established to be 1:12:4.

(4) Most of common ions do not interfere.

(5) The method can be applied to the spectrophotometric determination of germanium in some ginseng with satisfactory results.

\section{SEPARATION AND PRECONCENTRATION OF TRACE GERMANIUM}

In biological and environmental samples, germanium concentration is always lower than $\mu \mathrm{g} \cdot \mathrm{g}^{-1}$, although some color reaction systems have good analytical characteristics, a suitable separation and pre-concentration process was also required in order to obtain high precision and accuracy. In literature, main separation and pre-concentration method for trace amounts of germanium were coprecipitation, extraction and membrane separation; these are stated in the following in detail.

Some hydroxides of metals such as aluminum, cadmium, iron, gallium, lanthanum, and magnesium have large surfaces and can adsorb metal ions on the surface effectively; this property has been developed for the preconcentration of trace amounts of metal ions. Brindle et al. $/ 28 /$ have described a method for the determination of trace amounts of germanium in natural water by hydride generation atomic emission spectrometry with the co-precipitation in the presence of magnesium(II), gallium(III), calcium(II) and $\mathrm{HCO}_{3}{ }^{\circ}$. In general, the coprecipitation method in the batch mode is rather tedious and time-consuming. In order to resolve the problem, some new technologies were adopted in the literature. For examples, Shi et al. described an on-line with flow injection coprecipitation separation and preconcentration of germanium $/ 29 /$. The samples, each spiked with nickel(II) $\left(500 \mu \mathrm{g} \mathrm{ml}^{-1}\right)$, were introduced into the flow injection system using time-based injection, 


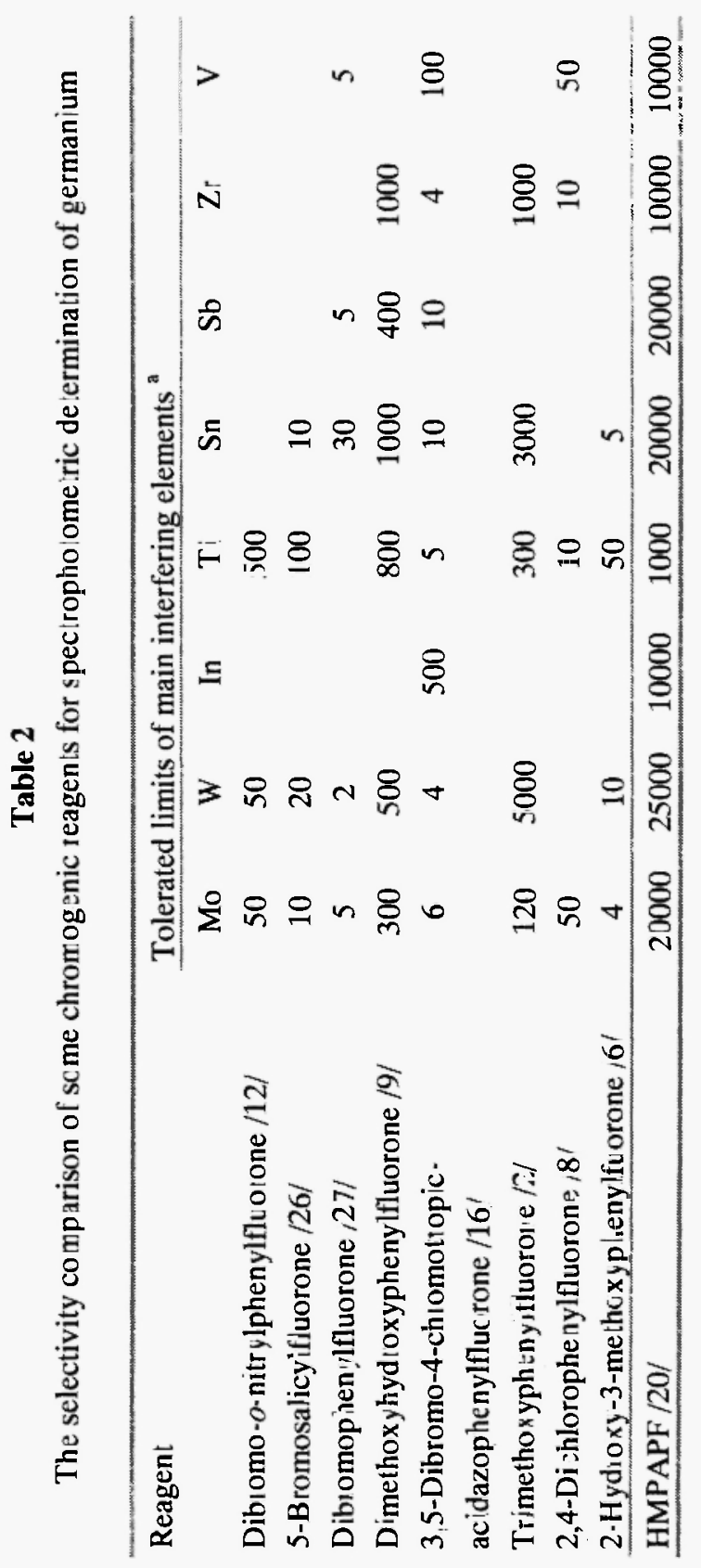


and mixed with a sodium hydroxide solution $\left(50 \mu \mathrm{g} . \mathrm{I}^{1}\right)$. Germanium was preconcentrated by coprecipitation with the generated nickel hydroxide precipitate. The precipitate is subsequently eluted with $20 \%(\mathrm{v} / \mathrm{v})$ phosphate acid solution and directed into analysis system; this method is simple and rapid, its detection limit $(3 \sigma)$ was $0.11 \mu \mathrm{g} \mathrm{I}^{-1}$ and the relative standard deviation was $5.6 \%(n=11)$ at the $10 \mu \mathrm{g} . \mathrm{I}^{-1}$ level. The extraction method included liquid-liquid, solid phase and cloud point extraction mainly. Liquidliquid extraction for the preconcentration of germanium often selected a chloroform solvent as extraction agent, a $9-10 \mathrm{~mol}$. ${ }^{\mathrm{I}^{-1}} \mathrm{HCl}$ was used to control the acidity of the solution; this method has a low enrichment time and recovery (about $95 \%$ ). Solid phase extraction technology used solid materials modified by functional groups as extraction agent; it has much higher enrichment times than liquid-liquid extraction. Gamze Gokturk et al. developed a solid phase method for preconcentration of germanium in water 130/. Silica modified by mercapto functional groups was applied as extraction agent, Using mercapto silica, satisfactory recovery values (95\%) were obtained at natural $\mathrm{pH}$, for germanate concentrations as low as $50 \mathrm{ng} . \mathrm{l}^{-1}$. Considering the highest preconcentration factor 400 -fold obtained, the sensitivity and 3s-detection limit of mercapto silica system can be expressed as 3.65 and $0.813 \mathrm{ng} . .^{-1}$, respectively. Chen et al. developed an organic solvent-soluble membrane for separation and preconcentration of germanium 131 , trace amounts of germanium(IV) was adsorbed on the organic membrane, then, the membrane was dissolved by the solvent and germanium was determined using spectrophotometry, this method has high preconcentration times. Recently, a new technology called as cloud point separation has been successfully employed for the preconcentration of germanium at trace levels from aqueous samples $/ 32 \%$. Germanium was taken into complex with quercetin in aqueous non-ionic surfactant Triton X-114 medium and concentrated in the surfactant rich phase by bringing the solution to the cloud point temperature $\left(19^{\circ} \mathrm{C}\right)$. The preconcentration of only $50 \mathrm{ml}$ of solution with $0.1 \%$ Triton X-114 and $2 \times 10^{-5}$ mol..$^{-1}$ quercetin at $\mathrm{pH}$ 6.4 gives a preconcentration factor of 200 . Under these conditions, the detection limit $3 s$ and the sensitivity of the cloud-point extraction system were 0.59 and $0.0620 \mu \mathrm{g} . \mathrm{l}^{-1}$, respectively. The extraction efficiency was investigated at low germanium concentrations $\left(10-30 \mu \mathrm{g} . \mathrm{l}^{-1}\right)$ and satisfactory recoveries(93-105\%) were obtained. 


\section{THE APPLICATION OF NEW SPECTROPHOTOMETRIC METHODS FOR DETERMINATION OF GERMANIUM}

In the past ten years, many new technologies have been applied to spectrophotometric determination of germanium. Among these, calculating spectrophotometry, double wavelength spectrophotometry, flow injection spectrophotometry and solid phase spectrophotometry were widely used in routine germanium analysis. Because the derivatives of phenylfluorone reagents can react with molybdenum, tungsten, titanium, tin, antimony, gallium, indium, zirconium, niobium and tantalum at similar conditions, it can produce serious interference to the spectrophotometric determination of germanium. For this reason, a scparation procedure was usually required in order to obtain a reliable result. Because germanium, molybdenum and tin et al. metal elements are important micro elements for humans and animals, these always require to be determined simultaneously. Calculating spectrophotometry is a strong tool for multi-element analysis. For example, Feng et al. achieved simultancous determination of germanium and tin by calculating spectrophotometry $133 /$. Germanium(IV) and tin(IV) react sensitively with phenylfluorone in the presence of CTMAB and $6.0 \mathrm{mol.} \mathrm{I}^{-1}$ $\mathrm{HCl}$ and result in formation of stable ternary complexes. Their maximum absorption lies at 510 and $514 \mathrm{~nm}$ respectively, showing the seriously overlapped absorption spectra. The principal component regression was applied for simultaneous determination of trace germanium and tin. The conditions of simultaneous determination were investigated, the simultaneous samples were analyzed by the proposed method and satisfactory results were obtained. Double wavelength standard addition spectrophotometry may be applied to eliminate interference and multi elemental analysis $/ 34,35 /$. Flow injection analysis (FIA) is a simple, rapid and highly reproducible technique that adapts to batch analysis. It has the advantages of exhausting little reagent and can be easily automated. Recently, FIA have been applied to determine kinds of analytes in a wide variety of fields $/ 37-39 \%$. With the application of photometric diode array detectors and computers, much attention has been paid to simultancous determination of multi-components by FIA. Compared with the conventional spectrophotometer, CCD diode array detectors can improve precision and signal to noise ratio and rapidly scan absorption spectrum. Application of the diode array detector in flow injection analysis can develop an auto-continuous analytical system for determining multiple components. Furthermore, overlapped spectra of analytes can be solved with 
powerful computational methods, such as wavelet analysis $/ 40,41 /$, Kalman filtering $/ 42 /$, partial least square $/ 43-45 /$, factor analysis $/ 46,47 /$, artificial neural networks $/ 48,49 /$ and so on. Partial least squares program is a usually optimal multivariate calibration method. For example, Zou et al. developed a new method for the simultaneous determination of germanium, molybdenum and tin using salicylflurone as chromogenic reagent by means of flow injection with a CCD diode array detector, and the multi-wavelength data thus obtained being processed by PLS algorithm. The proposed method was applied to the simultaneous determination of tin, germanium and molybdenum in food samples $150 /$. Moreover, solid phase spectrophotometry has very high sensitivity due to its enrichment of analyzes on solid materials; it has been widely used to determine trace amounts of germanium /51-52/.

\section{REFERENCES}

1. Zhao, X.R., Liang, S.X., Zuo, B.C., Talanta, 44 (6), 979 (1997).

2. Li, Z.J., Pan, J.M., Tang, J., Analytica Chimica Acta, 445 (2), 153 (2001).

3. Lopez-García, I., Campillo, N., Arnau-Jerez, I., Hernandez-Cordoba, M., Analytica Chimica Acta, 531 (1), 125 (2005).

4. Yang, L.L., Zhang, D.Q., Talanta, 56 (6), 1123 (2002).

5. Böyükbayram, A. Elif, Volkan, Mürvet, Spectrochimica Acta Part B: Atomic Spectroscopy, 55 (7), 1071 (2000).

6. Tang, J.H., Li, L., Chang, S.K., Chen, T.Y., Chinese Journal of Spectroscopy Laboratory, 21 (96), 1085 (2004).

7. Lin, C., Chinese Journal of Spectroscopy Laboratory, 21 (6), 1215 (2004)

8. Sai, Y., Li, S., Han, F.B., Spectroscopy and Spectral Analysis, 24 (11), 1404 (2004).

9. Kang, X.P., Pan, J.M., Physical Testing and Chemical Analysis Part B: Chemical Analysis, 39 (11), 636 (2003).

10. Kang, X.P., Pan, J.M., Journal of Xinjiang Medical University, 26 (6), 550 (2003)

11. Peng, C.H., Xi, C.S., Zeng, M.H., Yi, F.H., Yantai Normal University Journal (Natural Science), 19 (1), 21 (2003).

12. Li, F., Liu, J.J., Rock and mineral analysis, 19 (2), 158 (2000). 
13. Li, K.Q., Huang, M.X., Physical Testing and Chemical Analysis Part B: Chemical Analysis, 37 (3), 123 (2001).

14. Qi, L., Metallurgical Analysis, 22 (3), 46 (2002).

15. Mao, Y.F., Jiang, Y.C., Journal of Chongqing Polytechnic college, 15 (4), 59 (2000).

16. Huang, Y.P., Zhang, H.S., Li, X.Y., Huaxue Shij, 22 (3), 160 (2000).

17. Wang, Y.F., Zhong, M.H., Journal of Jiang Xi Normal University, 25 (3), 235 (2001).

18. Chen, Y., Zhu, R.H., Qiang, H., Ji, F., Gu, X.X., Microchemical Journal, 64, 93 (2000).

19. Huang, Y.P., Zhang, H.S., Li, X.Y., Chemical Research and Application, 9 (4), 348 (1997).

20. Zhou, X., Li, Z.J., Liu, H.Z., Yuan, R., Chinese Journal of Analysis Laboratory, in press.

21. He, X.W., Bi, S.W., Wang, H., Zhao, Z.G., Journal of Analytical Science, 21 (3), 298 (2005).

22. Yu, Y.M., Chen, Y.F., Guangdong Weiliang Yunsu Kexue, 5 (9), 49 (1998).

23. Cheng, G.X., Journal of Yunnan Institute of the Nationalities (Natural Science Edition), 8 (4), 37 (1999).

24. Huang, C., Yi, H., Physical Testing and Chemical Analysis: B Chemical Analysis, 40(12), 735 (2004).

25. 25.Cheng, G.X., Journal of Yunnan University, 22 (1), 57 (2000).

26. Qiu, C. Q., Liu, D., Luo, B., Physical Testing and Chemical Analysis: B Chemical Analysis, 30, 206 (1994).

27. Zhang, W. D., Wang, X. C., Physical Testing and Chemical Analysis: $B$ Chemical Analysis, 33, 170 (1997)

28. Brindle, I.D., Brindle, M.E., \& Le, X.C., Journal of Analytical Atomic Spectrometry, 6, 129 (1991).

29. Shi, J.B., Tang, Z.Y., Tan, C.H., Chi, Q., Jin, Z.X., Talanta, 56, 711 (2002).

30. Gamze Gokturk, Mehrdad Delzendeh, Murvet Volkan, Spectrochimica Acta Part B, 55, 1063 (2000).

31. Chen, Y., Zhu, R.H., Qiang, H., Ji, F.,Gu, X.X., Microchemical Journal, 64, 93 (2000).

32. Elif Boyukbayram, A., Murvet Volkan, Spectrochimica Acta Part B, 55, 1073 (2000). 
33. Feng, Y.B., Zhang, J.Z., Wen, B.Y., Yunna Metallurgy, 34 (1), 52 (2005).

34. Guo, Z.X., Li, M.B, Zhang, S.Y., Spectroscopy and Spectral Analysis, 18 (2), 247 (1998).

35. Wu, Y.S., Zhao, X.N., Chinese Journal of Analytical Chemistry, 26 (8), 977 (1998)

36. Z. Shulin, X. Xinquan, Y. Gang, Y. Bo, Talanta, 46, 845 (1998).

37. M.F. Mousavi, A. Jabbari, S. Nouroozi, Talanta, 45, 1247 (1998).

38. N. Kiba, S. Limin, S. Yokose, M.T. Kazue, T.T. Suzuki, Analytica Chimica Acta, 378, 169 (1999).

39. J.L.F.C. Lima, M.C. Delerue, M. Vaz, et al., Fresenius Journal Analytical Chemistry, 364, 266 (1999).

40. E. Dinç, D. Baleanu, Talanta, 59, 707 (2003).

41. R. Shouxin, G. Ling, Talanta, 50, 1163 (2000).

42. H.N.A. Hassan, B.N. Barsoum, I.H.I. Habib, J. Pharm. Biomed. Anal., 20, 315 (1999).

43. F. Salinas, I. Paya, D. Orbe, Analytica Chimica Acta, 313, 103 (1995).

44. J. Ghasemi, Sh. Ahmadi, K. Torkestani, Analytica Chimica Acta, 487, 181(2003).

45. T. Khayamian, A.A. Ensafi, B. Hemmateenejad, Talanta, 49, 587 (1999).

46. H. Schneeweiss, H. Mathes, Journal of Multivariate Analysis, 55, 105 (1995).

47. S. Hanxi, C. Huowei, Chin. J. Metallurgical Analysis, 14, 26 (1994).

48. M. Kompany-Zareh, A. Massoumi, Sh. Pezeshk-Zadeh, Talanta , 48, 283 (1999).

49. A. Safavi, H. Abdollahi, M.R. Hormozi Nezhad, Talanta, 59, 515 (2003).

50. Zou, X.L., Li, Y.Q., Li, M.L., Zheng, B., Yang, J.G., Talanta, 62, 719 (2004).

51. Ni, G., Yuan, L., Gao, J.Z., Chinese Journal of Analysis Laboratory, 20 (5), 17 (2001).

52. Luo, D.C., Yi, P.G., Chen, A.G., Chinese Journal of Rare Metals, 27 (2), 314 (2003). 
